\title{
Experimental Study on the Softening Characteristics of Sandstone and Mudstone in Relation to Moisture Content
}

\author{
Gui-chen Li, ${ }^{1,2}$ Chong-chong Qi, ${ }^{1,3}$ Yuan-tian Sun, ${ }^{1}$ Xiao-lin Tang, ${ }^{1}$ and Bao-quan Hou ${ }^{1}$ \\ ${ }^{1}$ School of Mines, China University of Mining and Technology, Xuzhou 221116, China \\ ${ }^{2}$ Key Laboratory of Deep Coal Resource Mining, Ministry of Education of China, Xuzhou 221116, China \\ ${ }^{3}$ School of Civil, Environmental and Mining Engineering, University of Western Australia, Perth, WA 6009, Australia \\ Correspondence should be addressed to Chong-chong Qi; 21948042@student.uwa.edu.au
}

Received 19 December 2016; Accepted 15 January 2017; Published 22 February 2017

Academic Editor: M. I. Herreros

Copyright (C) 2017 Gui-chen Li et al. This is an open access article distributed under the Creative Commons Attribution License, which permits unrestricted use, distribution, and reproduction in any medium, provided the original work is properly cited.

\begin{abstract}
The kinetics of fluid-solid coupling during immersion is an important topic of investigation in rock engineering. Two rock types, sandstone and mudstone, are selected in this work to study the correlation between the softening characteristics of the rocks and moisture content. This is achieved through detailed studies using scanning electron microscopy, shear tests, and evaluation of rock index properties during exposure to different moisture contents. An underground roadway excavation is simulated by dynamic finite element modeling to analyze the effect of moisture content on the stability of the roadway. The results show that moisture content has a significant effect on shear properties reduction of both sandstone and mudstone, which must thus be considered in mining or excavation processes. Specifically, it is found that the number, area, and diameter of micropores, as well as surface porosity, increase with increasing moisture content. Additionally, stress concentration is negatively correlated with moisture content, while the influenced area and vertical displacement are positively correlated with moisture content. These findings may provide useful input for the design of underground roadways.
\end{abstract}

\section{Introduction}

The physical and mechanical properties of rocks, especially rock strength measurement and classification, are fundamental to the design and engineering of rock structures such as underground roadways and tunnels. This is particularly true when such structures are built in mudstone and sandstone, which are two most widely distributed rock types encountered in underground mines. Such rock types are also frequently encountered in underground coal mining operations, which are increasing in depth and complexity. As such, fluid-solid interaction becomes important, as it influences these physical and mechanical properties, as well as the microstructure, of rock.

Approximately $90 \%$ of the rock slope failure is caused by groundwater flow in porous and fractured rock; $60 \%$ of the hazards in the coal mine are associated with groundwater and $30 \%-40 \%$ of the hydropower dam failure is due to the seepage of water [1]. Recently, water injection was found to be effective in rock-burst relief and prevention [2,3]. All of these result in a need to investigate the softening characteristic of mudstone and sandstone under different water contents.

The mechanical properties of rocks with different moisture contents have been widely studied. Van Eeckhout and Peng [4] studied the effect of relative humidity on the mechanical properties of shales and found that with an increase in moisture content there is a reduction in uniaxial compression strength (UCS) and elastic modulus and an increase in Poisson's ratio. Colback et al. [5] investigated the effects of moisture on two quartzitic rock types and found that the moisture content had a major influence on the compressive strength characteristics. Lajtai et al. [6] indicated, with time-dependent tests, that water has a substantial effect on creep strain, static fatigue, and low crack propagation velocity. Ojo and Brook [7] found that moisture content, within certain values of relative saturation, has a great influence on the stable minimum or maximum strength attained in the rock. 
Okubo et al. [8] found that compressive strength decreases significantly with an increase of moisture content, but an observed increase in strength with loading rate did not depend on moisture content. Feucht and Logan (1990) found that the friction factor of a saturated sandstone was reduced by $15 \%$, while Hawkins and Mcconnell [9] investigated the influence of water content on the strength and deformability of 35 different British sandstone samples and proposed an empirical relationship between water content and UCS.

Valès et al. [10] found that rock mechanical behavior in shale is sensitive to the saturation state and is also linked to stratification in the shale and its relative orientation to the applied stress. Pham et al. [11] found that elastic parameters and compressive strength of mudstone depend strongly on the effect of suction, while Erguler and Ulusay [12] showed that, from an oven-dried to saturated clay-bearing rock, an increasing water content caused reductions of $90 \%$ in UCS, $93 \%$ in modulus of elasticity, and $90 \%$ in tensile strength, respectively. Zhou et al. [13] carried out a dynamic compressive experiment on cement mortar with different water contents and found that the dynamic compressive strength of saturated specimens was $23 \%$ lower than that of completely dry specimens.

Additionally, the analysis of microstructures has long been an effective method to study soil and rock properties. Gianelli et al. [14] used SEM-EDAX to analyze the texture of montmorillonite during their study of water-rock interaction. Chai et al. [15] found that the quantity and size of pores in bedrock increased after the introduction of water, which decreased the sliding strength of the soil. Duraiswami and Shaikh [16] employed the SEM in the analysis of fluid-rock interaction in carbonatite. The results showed that exotic minerals in the siderite carbonatite did not crystallise from carbonate magma.

Chai et al. [17] studied the effect of water-rock interaction on the mechanical properties of marly rocks and found that the changes of minerals and microstructure can trigger shallow slope failure and develop deep creep deformation along some crash zones in the reservoir shoreline. Çelik et al. [18] studied photomicrographs and textures of the Ayazini tuffs using SEM. Zhang et al. [19] used XRD, SEM, and energy dispersive spectrometry to study alteration of physical and chemical properties, mineral composition, and microstructures caused by the removal of free iron oxides.

In most water-rock interaction studies, only mechanical property changes are considered and microstructural changes are typically ignored. Limited studies have been conducted on these changes on both macro- and microscopic scales. Therefore, this paper presents a series of experiments that investigate the process and characteristics of mudstone and sandstone during saturation. Not only is the relationship between mechanical properties and moisture content discussed, but we also analyze the microstructure changes under different moisture content. From this, detailed information about the influence of moisture content is obtained with regard to its influence on the softening characteristics of mudstone and sandstone.

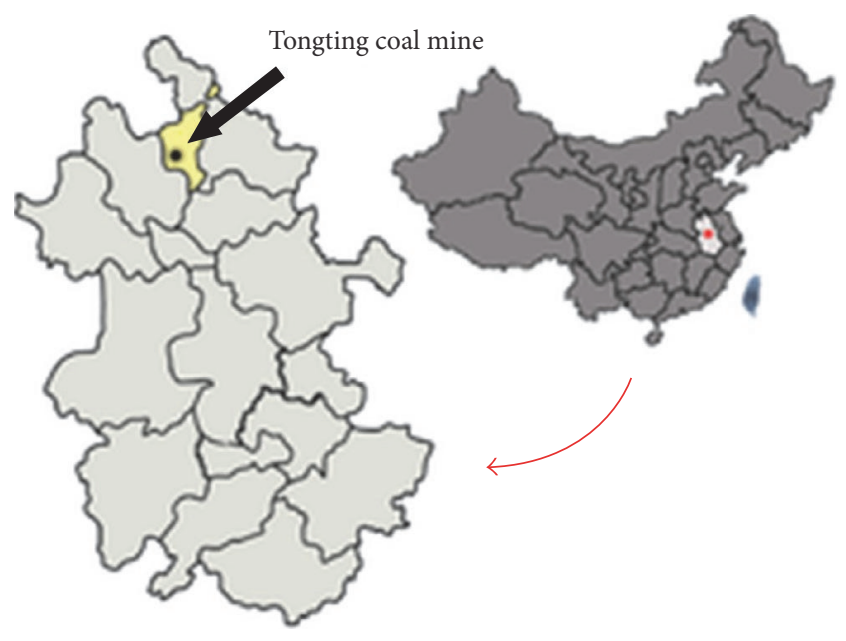

FIGURE 1: Location map of Tongting coal mine.

\section{Geological Background}

The main study area is the 8214 working face of the Tongting Colliery, located in Huaibei City, Anhui, China (Figure 1). This colliery operates at a depth of $616.8-665.3 \mathrm{~m}$ in the Permian system with a 2 -m-thick immediate roof consisting of mainly siltstone and sandstone. The thickness of the predominantly mudstone floor is about $0.7 \mathrm{~m}$.

There is water that has remained in the goaf area of the 8212 working face, which is considered likely to enter the working face of 8214 and cause instability of both the roof and floor. There is also the possibility of hazardous water inrush. Therefore, the study of rock softening characteristics caused by different moisture contents and saturation is of great importance to the safety and operability of the Tongting Colliery.

\section{Sample Preparation}

The samples used in the experiments are typical undisturbed samples of mudstone and sandstone taken from roof and floor of the 8214 working face. To minimize moisture content changes during transportation, the undisturbed samples were first sealed in plastic bags and then wrapped in gunny bags immediately after being obtained. They were then transported to the laboratory and processed according to the test standards [20]. 28 sandstone samples and 22 mudstone samples, both of $\Phi 50 \mathrm{~mm} \times 50 \mathrm{~mm}$ size, are used in the shear test.

\section{Methodology}

4.1. X-Ray Diffraction Analyses. XRD is an analytical technique in which a prepared sample is bombarded with an $\mathrm{X}$ ray beam at varying angles to determine its mineralogy [21]. The XRD analysis of the mudstone and sandstone samples was carried out at the Advanced Analysis \& Computation Center, China University of Mining and Technology. The various mineral phase components of the mudstone and sandstone specimens were determined from carefully prepared 


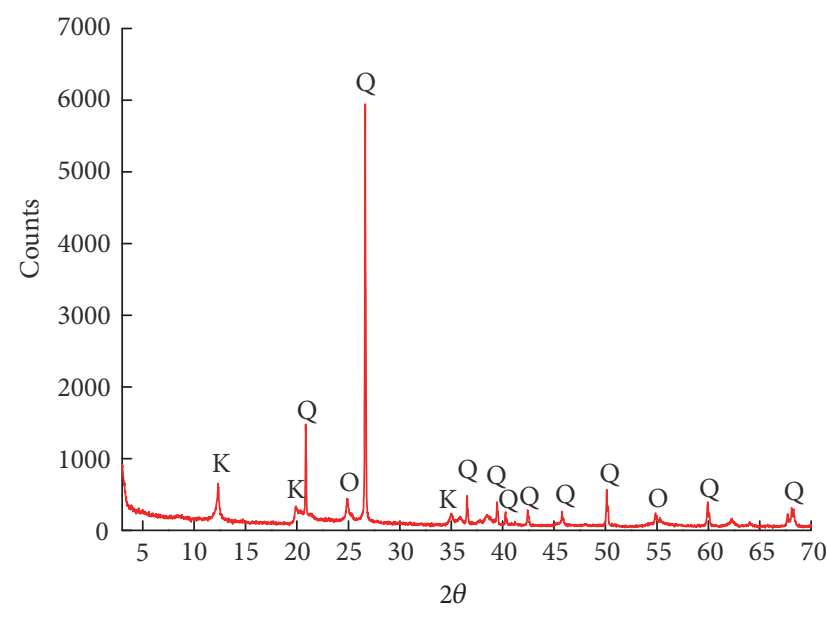

Q: quartz

K: kaolinite

O: others

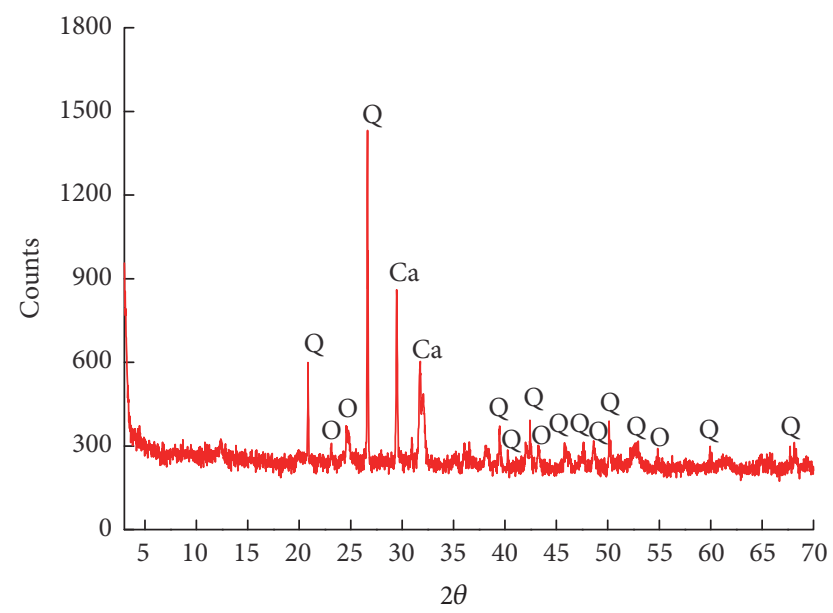

Q: quartz

Ca: calcium silicate

O: others

(a)

(b)

FIGURE 2: XRD analytical patterns of samples: (a) sandstone; (b) mudstone.

TABLE 1: Minerals composition of mudstone and sandstone (\%).

\begin{tabular}{|c|c|c|c|c|c|c|c|}
\hline Rock type & Quartz & Calcium silicate & Kaolinite & Feldspar & Chlorite & Illite & Others \\
\hline Mudstone & 27.70 & - & 56.10 & - & - & 11.20 & 5.00 \\
\hline Sandstone & 70.20 & 27.10 & - & - & - & - & 2.70 \\
\hline
\end{tabular}

powdered samples (325 mesh). A polarizing microscope was used to visually inspect and petrographically describe the powdered mudstone and sandstone samples. Once XRD diffractograms were obtained, phase identification and component analysis was carried out using Jade (Materials Data Inc., California, USA).

Diffractograms of the sandstone and mudstone are shown in Figure 2, and the XRD results after Jade analysis are given in Table 1. Bragg-Brentano reflection focusing, which is the most widely used diffractometric arrangement, was used during quantitative phase analysis [22]. The diffraction pattern of the sandstone sample confirms the presence of quartz $(70.2 \%)$ and calcium silicate (27.1\%). Clay minerals were identified in the mudstone samples, of which kaolinite is the main clay mineral.

4.2. Shear Tests. Specimens for rock mechanical tests were prepared in the laboratory using a core drilling machine; the core specimens were machined according to standards of the International Society for Rock Mechanics [23]. All samples were weighed in their initial state to determine their natural moisture content. Then, a natural immersion test was designed, in which both mudstone and sandstone samples were saturated with water for different times to obtain samples with different moisture contents. Samples with short immersion times were sealed and stored upside down.

Shear tests were carried out in accordance with methods suggested by the ISRM [23]. Figure 3 shows a few of the rock samples prepared for the shear tests.
4.3. Scanning Electron Microscopy. Scanning electron microscopy is a well-established method for the characterization of surfaces in ultrahigh vacuum (UHV), high vacuum (HV), and low vacuum (LV) conditions in many different fields of research [24]. In this paper, SEM was used to investigate the surface microstructure of the samples at different moisture contents by comparing various SEM images as moisture contents were changed. SEM images were processed using Image-Pro Plus (Media Cybernetics Inc., Maryland, USA) to obtain the key pore structure parameters, such as number and area. The image processing steps included noise removal, binarization, pore selection, and counting. Additionally, the surface porosity of the samples with different moisture contents were calculated and analyzed.

\section{Results and Discussions on Experiments Studies}

5.1. Rock Immersion Test Results. As described above, mudstone and sandstone samples were subjected to immersion testing. The different immersion times for the sandstone samples were $1,2,3,4,5,6$, and 8 days. Mudstone samples were saturated in water for: 1, 2, 3, 4, and 6 days.

The average moisture content of the mudstone and sandstone samples was then calculated for each immersion time and curves of moisture content and immersion time were generated (Figure 4).

It was found that, at the beginning of immersion, the moisture content of both mudstone and sandstone increased dramatically. The moisture content of mudstone increased 


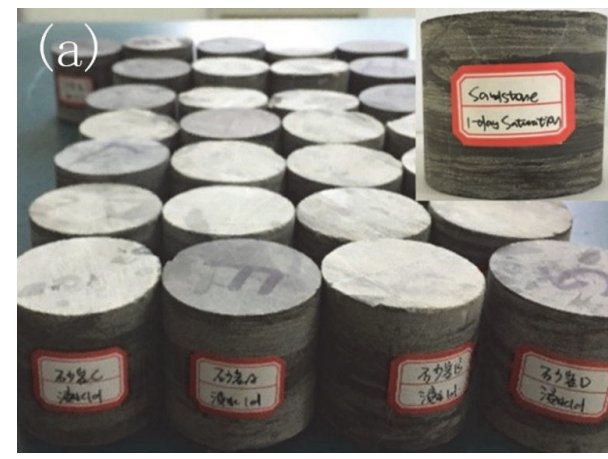

(a)

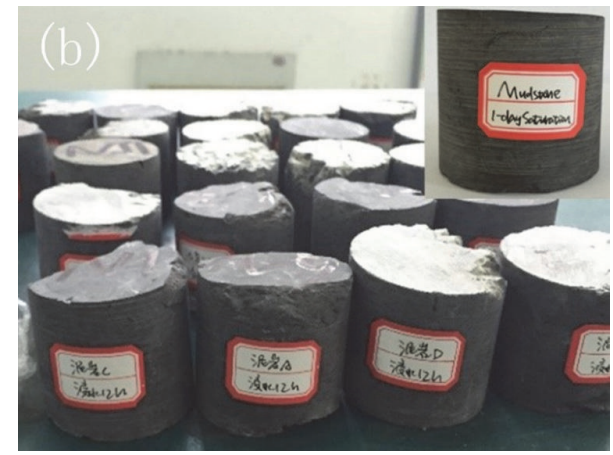

(b)

FIgURE 3: Shear test samples: (a) sandstone; (b) mudstone.

TABLE 2: The mechanical properties of rock samples under different moisture content.

\begin{tabular}{|c|c|c|c|c|}
\hline Rock type & Moisture content & $\begin{array}{c}\text { Shear } \\
\text { strength/MPa }\end{array}$ & Cohesion/MPa & $\begin{array}{c}\text { Internal friction } \\
\text { angle } /{ }^{\circ}\end{array}$ \\
\hline \multirow{7}{*}{ Sandstone } & $1.27 \%$ & 64.95 & 21.68 & 31.93 \\
\hline & $1.85 \%$ & 45.01 & 15.54 & 29.20 \\
\hline & $1.91 \%$ & 33.97 & 14.73 & 29.14 \\
\hline & $2.16 \%$ & 30.14 & 13.06 & 29.16 \\
\hline & $2.24 \%$ & 30.10 & 12.65 & 28.82 \\
\hline & $2.29 \%$ & 30.04 & 12.64 & 28.62 \\
\hline & $2.27 \%$ & 29.96 & 12.40 & 28.88 \\
\hline \multirow{5}{*}{ Mudstone } & $1.97 \%$ & 15.44 & 5.95 & 28.18 \\
\hline & $3.41 \%$ & 9.38 & 4.98 & 27.20 \\
\hline & $4.59 \%$ & 8.01 & 4.60 & 26.19 \\
\hline & $4.84 \%$ & 7.75 & 4.36 & 26.14 \\
\hline & $4.97 \%$ & 8.03 & 4.27 & 26.57 \\
\hline
\end{tabular}

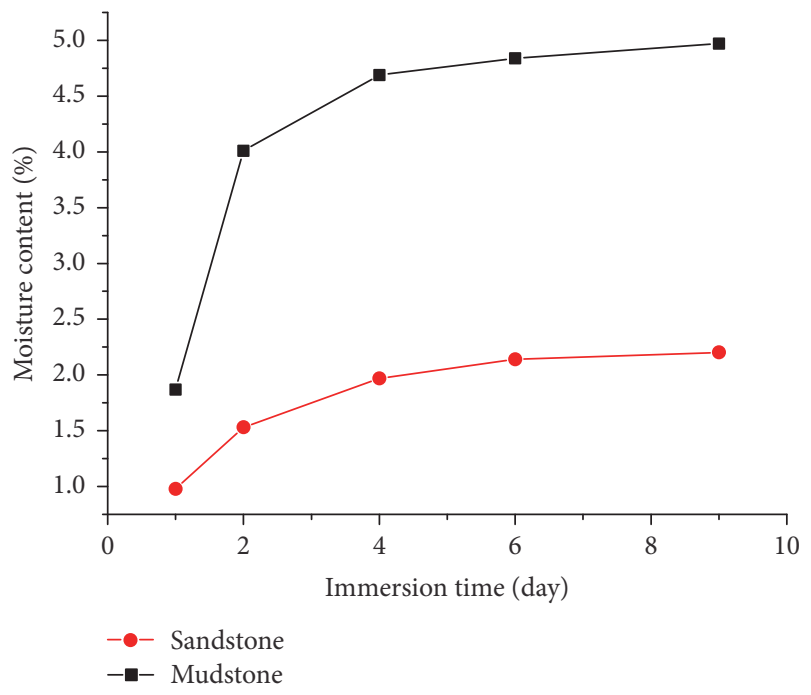

FIGURE 4: Curve of moisture content and saturation time.

to $4.59 \%$ after 3 days' saturation, and that of the sandstone increased to $1.91 \%$ after 3 days. The rate of increase in moisture content becomes reduced with increasing immersion time, and the moisture content of mudstone and sandstone increased to only $4.97 \%$ and $2.27 \%$, respectively, after 6 days' and 8 days' saturation.

5.2. Shear Test Results. The mechanical properties investigated in this paper include shear strength, cohesion, and internal friction angle. Changes in these mechanical properties at different moisture contents are shown in Table 2.

Regression analysis was carried out to investigate the relationship between moisture content and the mechanical properties. Curves of best-fit for the experimental data take the general form of $y=A \cdot \exp (-x / t)+B$ (Figure 5) and the expressions and correlation coefficients of shear strength, cohesion and internal friction angle according to moisture content are presented in Table 3. Overall, the mechanical properties of the mudstone were found to be significantly lower than those of the sandstone, and all investigated mechanical properties tend to decrease with increasing moisture content.

Figure 4(a) further manifests that the shear strength of sandstone and mudstone decreases with the increase of water content. At moisture contents of $1.27 \%$ and $1.97 \%$ (1 day immersion), the shear strengths of the sandstone and mudstone were $64.95 \mathrm{MPa}$ and 15.44 $\mathrm{MPa}$, respectively. This 
TABLE 3: The expression between mechanical properties and moisture content.

\begin{tabular}{lccc}
\hline Rock type & Mechanical properties & Expression & $R^{2}$ \\
\hline \multirow{3}{*}{ Sandstone } & Shear strength & $Y=199.37 \times \exp (-x / 1.01)+8.18$ & 0.93 \\
& Cohesion & $Y=49.98 \times \exp (-x / 1.05)+6.75$ & 0.94 \\
\hline \multirow{3}{*}{ Mudstone } & Internal friction angle & $Y=142.92 \times \exp (-x / 0.34)+28.67$ & 0.91 \\
& Shear strength & $Y=56.41 \times \exp (-x / 1.01)+7.45$ & 0.94 \\
& Cohesion & $Y=4.98 \times \exp (-x / 4.00)+2.90$ & 0.92 \\
\hline
\end{tabular}

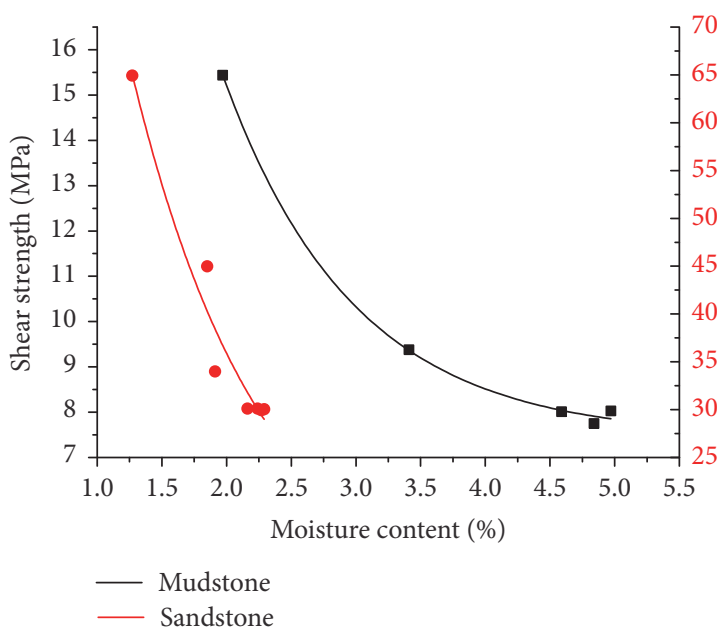

(a)

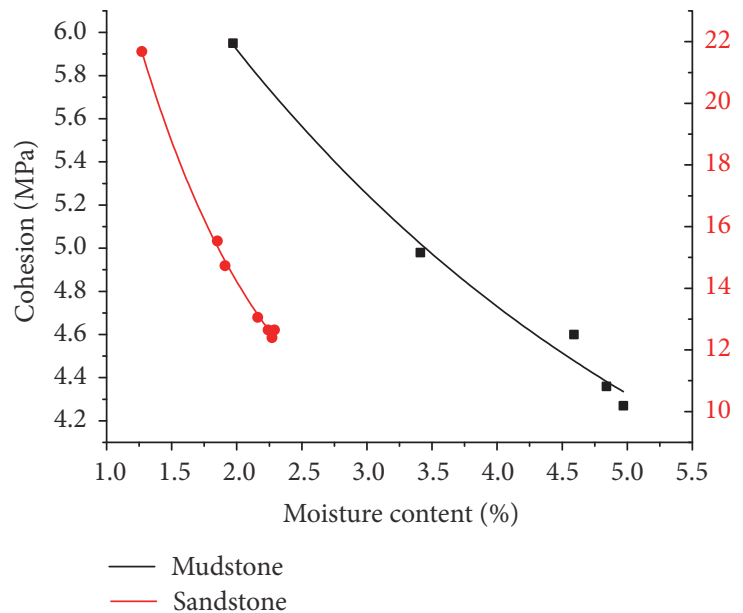

(b)

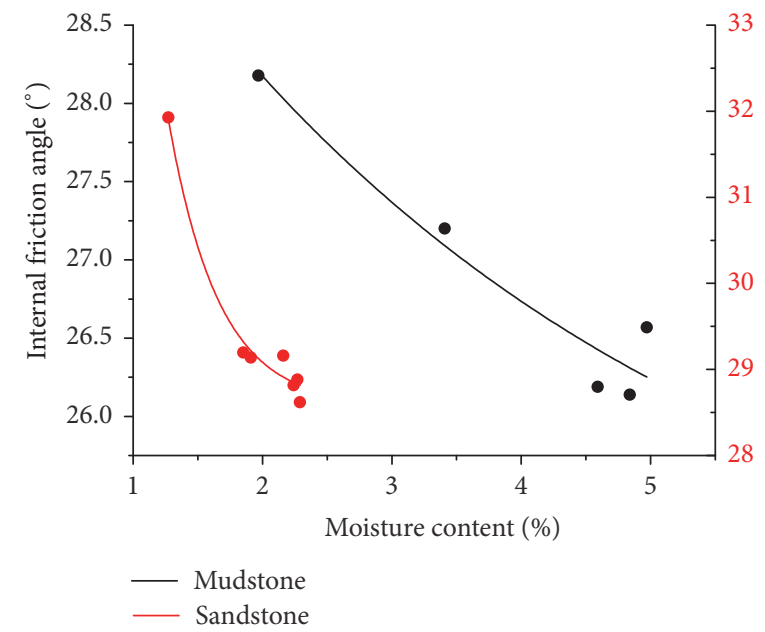

(c)

FIGURE 5: Curve of rock mechanical properties with moisture content: (a) compressive strength; (b) cohesion; (c) internal friction angle.

value in the sandstone decreased to $29.96 \mathrm{MPa}$ after 9 days of immersion while the value in mudstone decreased to $8.03 \mathrm{MPa}$ after 6 days of immersion. This accords well with previous observations.

Figures 5(a), 5(b), and 5(c) present the variation of cohesion and internal friction angle with different water contents. Changes in cohesion with moisture content show a similar trend to that observed in compressive strength. Cohesion decreased by $57.2 \%$ in the sandstone and by $71.76 \%$ in the mudstone. Compared with other mechanical properties, the changes in internal friction angle are different: the internal friction angle decreased by $90.44 \%$ in the sandstone and by $94.29 \%$ in the mudstone.

Stress-strain curves obtained during the experiments were analyzed to study the softening characteristics caused by different moisture contents. Stress-strain curves obtained at different moisture contents with a shear angle $45^{\circ}$ are shown in Figure 6.

It can be concluded from the curves that dramatic brittle failure occurs when the moisture content is low for both 


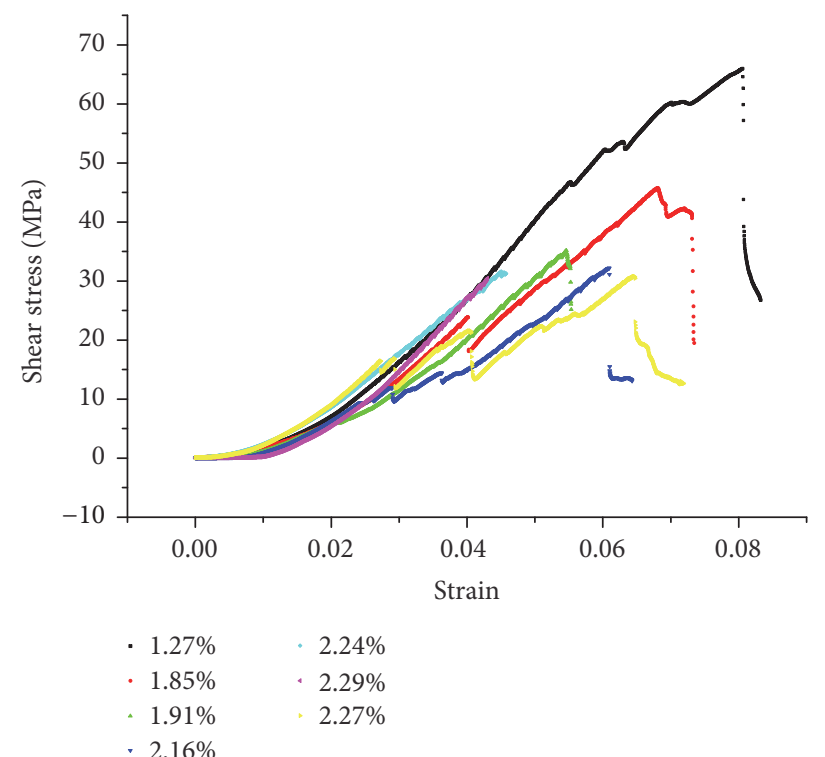

(a)

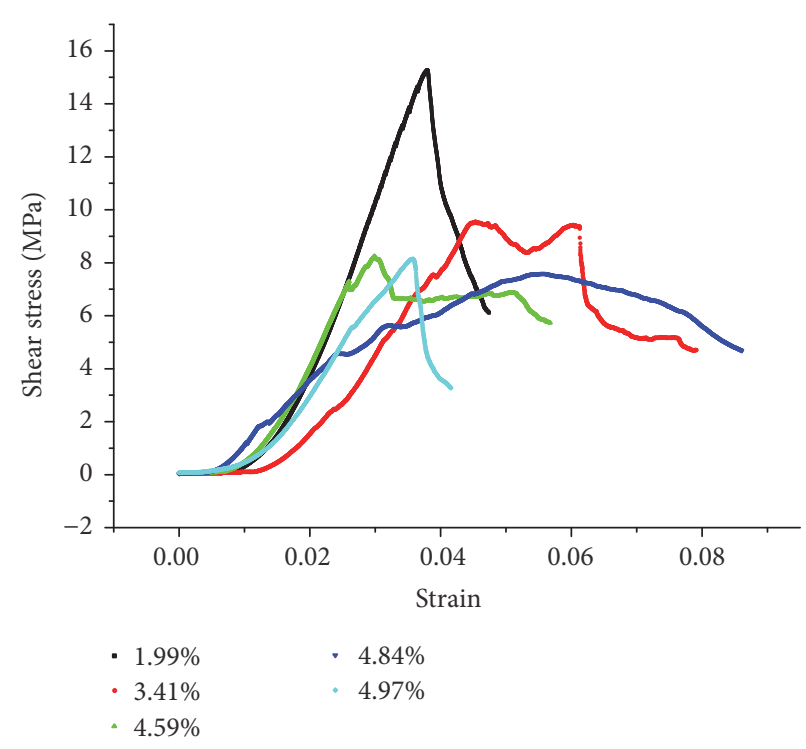

(b)

FIGURE 6: Stress-strain curve: (a) mudstone; (b) sandstone.

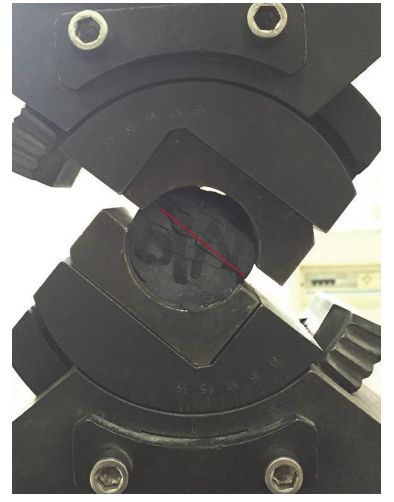

(a)

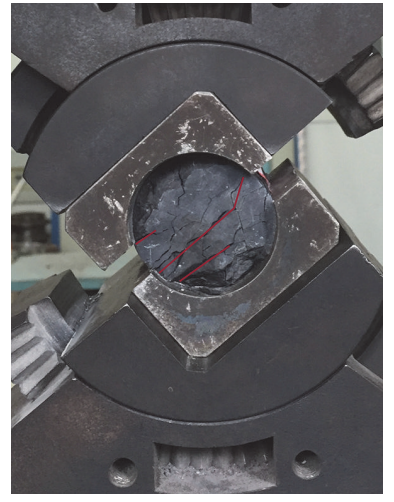

(b)

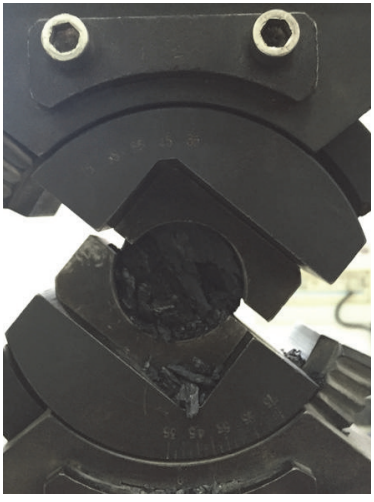

(c)

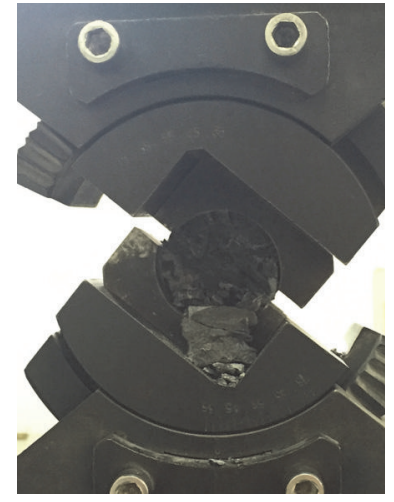

(d)

Figure 7: Failure mode of mudstone under different moisture content: (a) 1.97\%; (b) 3.41\%; (c) 4.59\%; (d) 4.97\%.

mudstone and sandstone. Shear stress drops suddenly after failure. With increasing moisture content, the properties of creep in the rock samples become increasingly important, as slow rupturing appears in both mudstone and sandstone with only moderate decreases in shear stress after rock failure.

The softening characteristics of rock samples can also be illustrated by the failure modes of mudstone and sandstone (Figures 7 and 8). Failure occurs along one shear failure surface when the moisture content is low and, in most cases, the shear failure surface is parallel to the shear angle. More shear failure surfaces appear with an increase in moisture content and, ultimately, both mudstone and sandstone samples break into numerous small pieces after shear failure.

\subsection{Microscopic Analysis with Different Moisture Content.} Mudstone and sandstone block samples with different moisture contents were analyzed using SEM. The blocks were 1 $\times 1 \times 0.5 \mathrm{~cm}$ in size, gold sprayed in a laboratory, and then fixed on the observation platform. The SEM analysis was conducted at the Advanced Analysis \& Computation Center using a FEI QuantaTM250 instrument, with which 500, 2000, 4000 , and 8000 multiple SEM images were captured. Only 4000 multiple SEM images were selected for analysis in this paper.

SEM images of the mudstone with different moisture contents are shown in Figure 9. Figure 9(a) shows an SEM image of the initial mudstone sample with a moisture content of $1.54 \%$. Very few micropores can be observed, while tortuosity of the micropores is clearly visible. SEM images of the mudstone with moisture contents of $1.87 \%$, 2.96\%, and 4.31\% are shown in Figures 9(b), 9(c), and 9(d), respectively. Furthermore, binary images of the SEM images were extracted using Image-Pro Plus (Figure 10).

For the sandstone, only the initial state (moisture content of $0.91 \%$ ) and final state (7-day immersion; moisture content of $2.18 \%$ ) were analyzed. The SEM images and binary images are shown in Figures 11 and 12, respectively. 


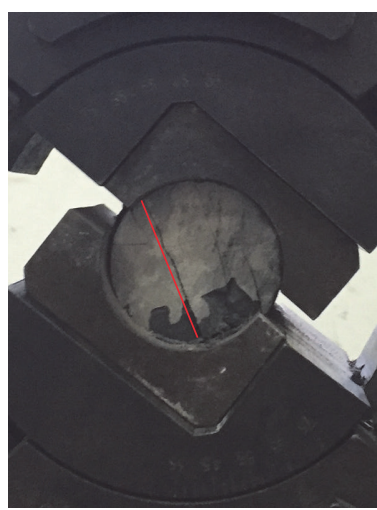

(a)

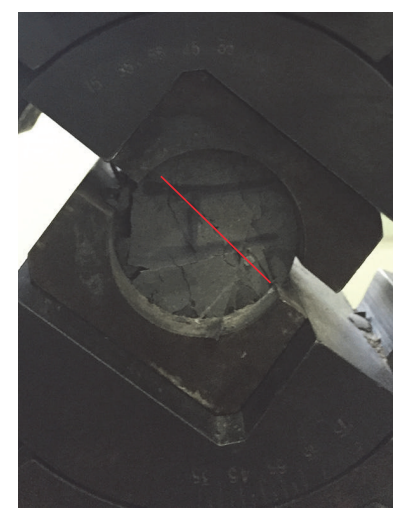

(b)

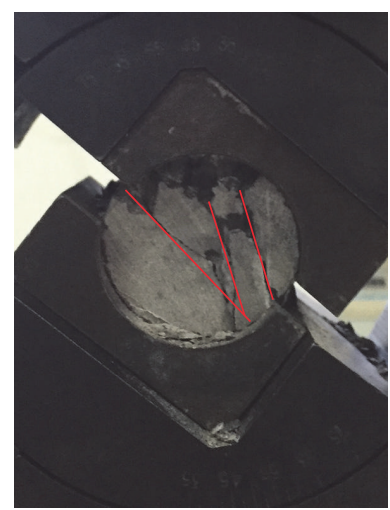

(c)

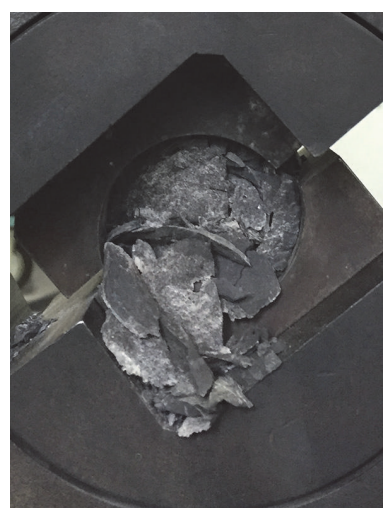

(d)

FiguRE 8: Failure mode of sandstone under different moisture content: (a) 1.27\%; (b) 1.91\%; (c) 2.16\%; (d) $2.29 \%$.

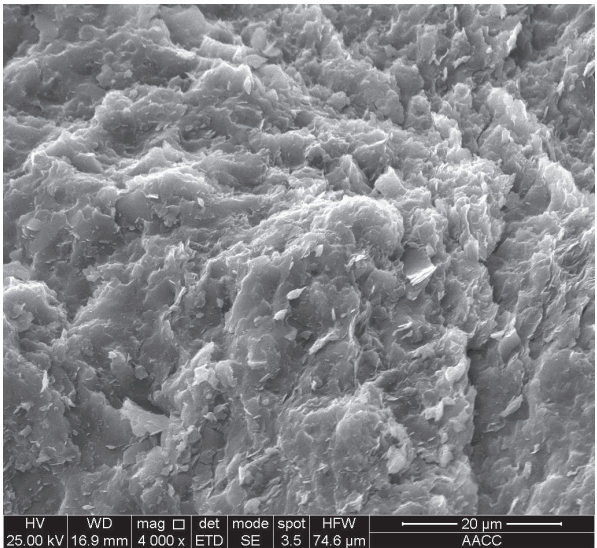

(a)

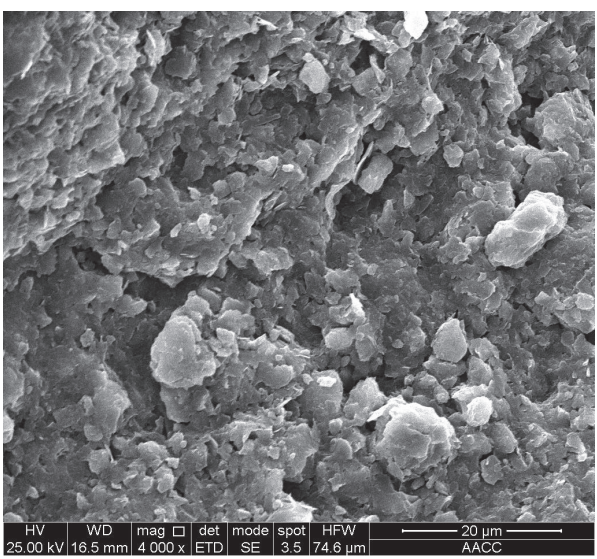

(c)

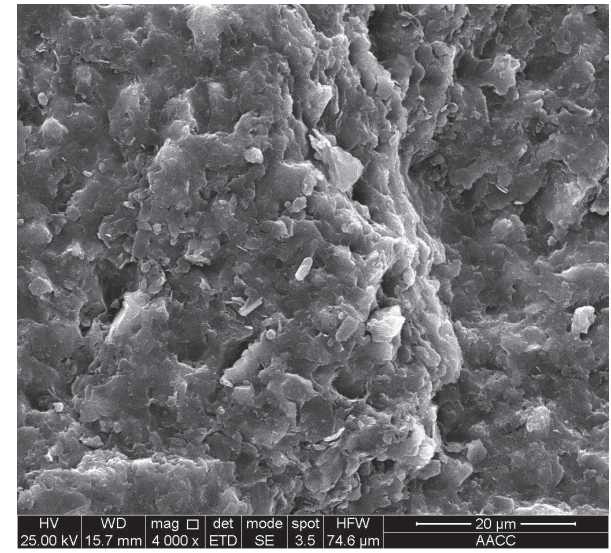

(b)

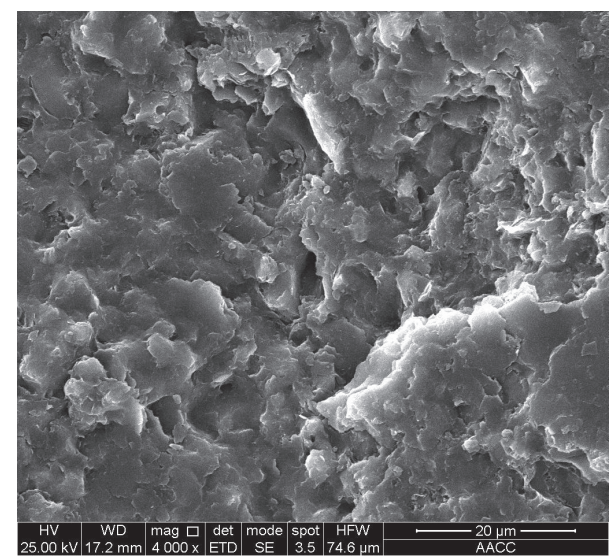

(d)

Figure 9: Microstructure of mudstone with different moisture content: (a) 1.54\%; (b) 1.87\%; (c) 2.96\%; (d) $4.31 \%$.

The parameters of the surface micropores, such as number, total area, and diameter, were simultaneously counted from the binary images and the surface porosity was calculated. Table 4 lists the parameter variations of the micropores of the sandstone and mudstone with different moisture contents. Figure 13 shows histograms and line graphs of variation of the parameters of the micropores.
Overall, the number of micropores was observed to increase with increasing moisture content and, during immersion, water primarily entered the original pores and fractures. Different swelling properties of different minerals likely led to unbalanced stresses inside the rock, resulting in formation of new fractures. This not only caused an increase in the number of micropores, but also an increase in the 


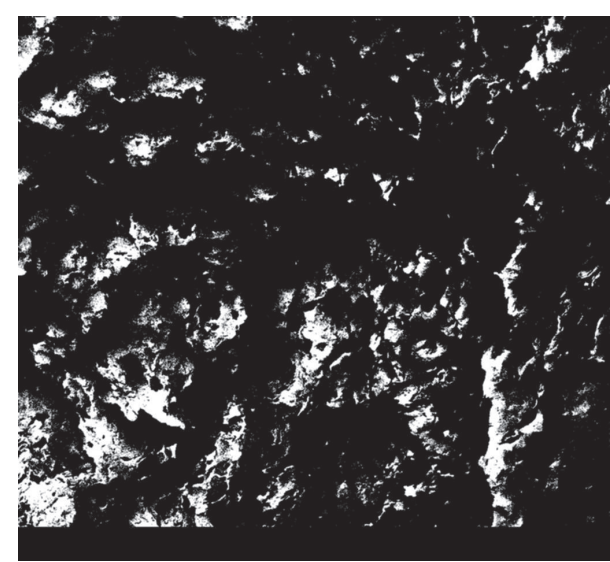

(a)

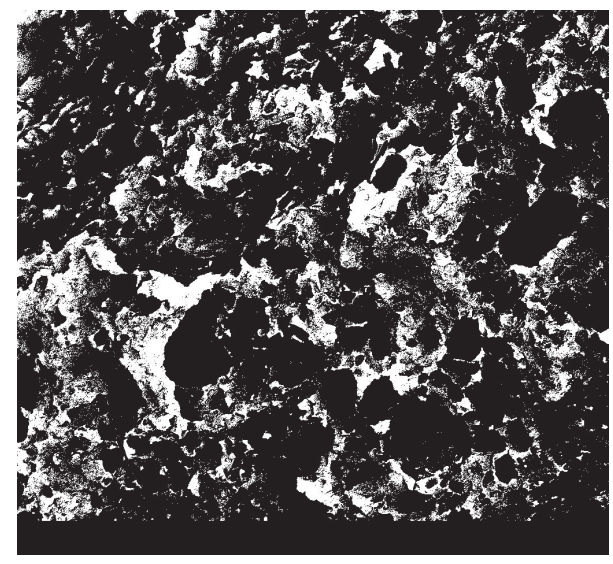

(c)

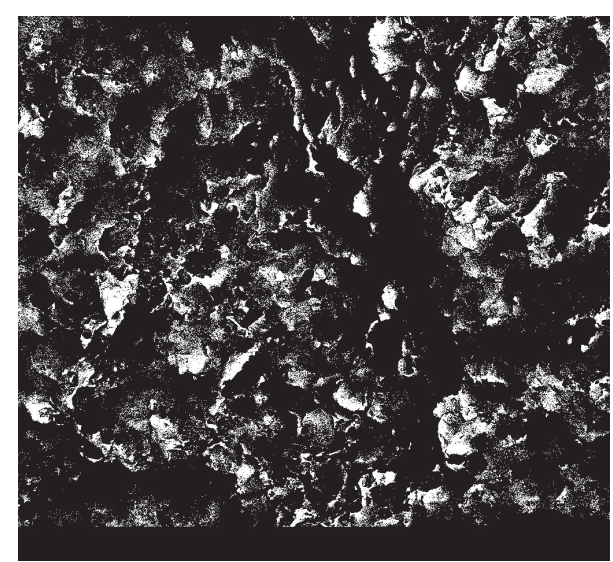

(b)

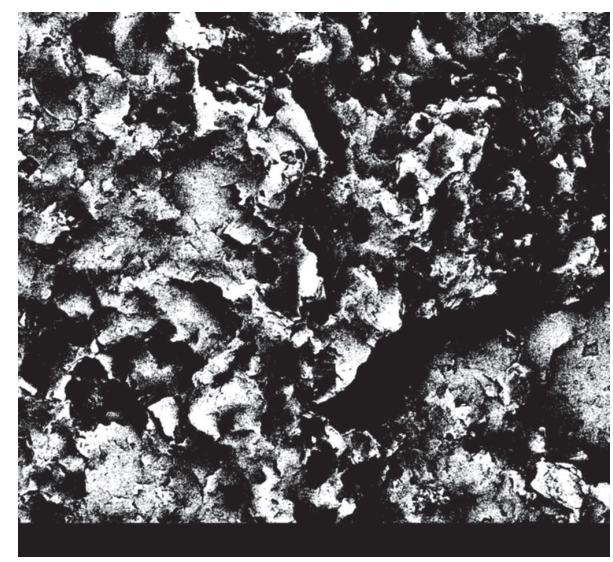

(d)

FiguRE 10: Binary images of mudstone with different moisture content (white: micropores): (a) 1.54\%; (b) 1.87\%; (c) $2.96 \%$; (d) $4.31 \%$.

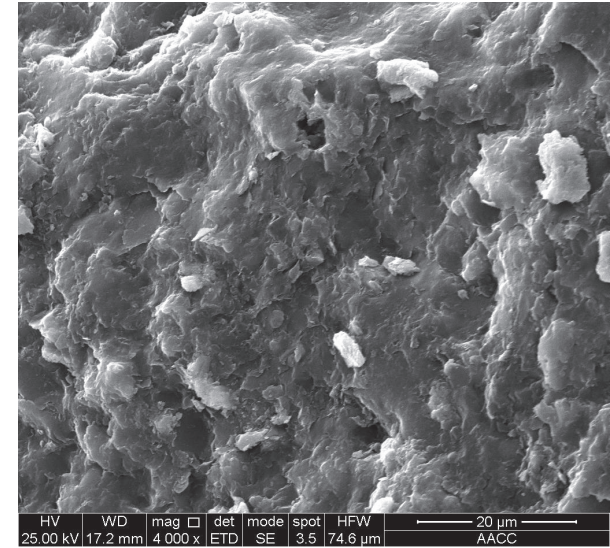

(a)

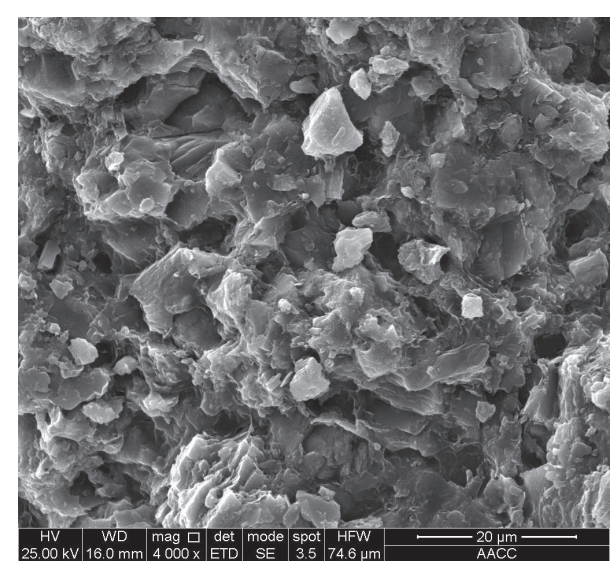

(b)

Figure 11: Microstructure of sandstone with different moisture content: (a) 0.84\%; (b) $2.10 \%$.

total area and surface porosity. Also, seepage of water into the rock led to an increase in interconnectedness of the new micropores and fractures, forming larger ones, and thus increasing the area and diameter of the micropores.

\section{Numerical Modelling}

6.1. Basic Equation of Coupled Model of Seepage and Stress. The following equations describe the quantification of the 


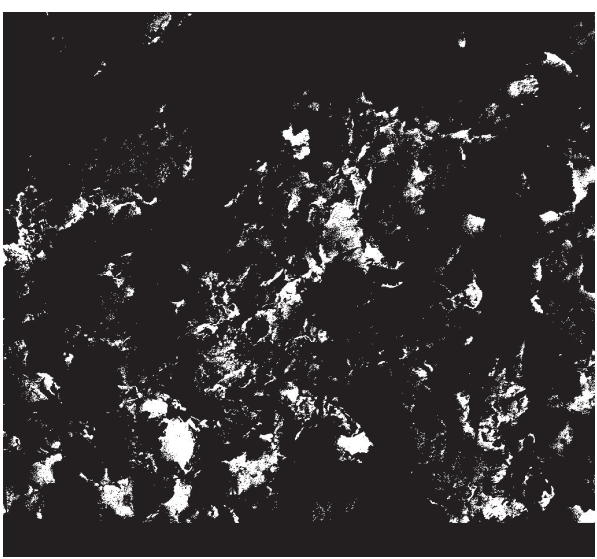

(a)

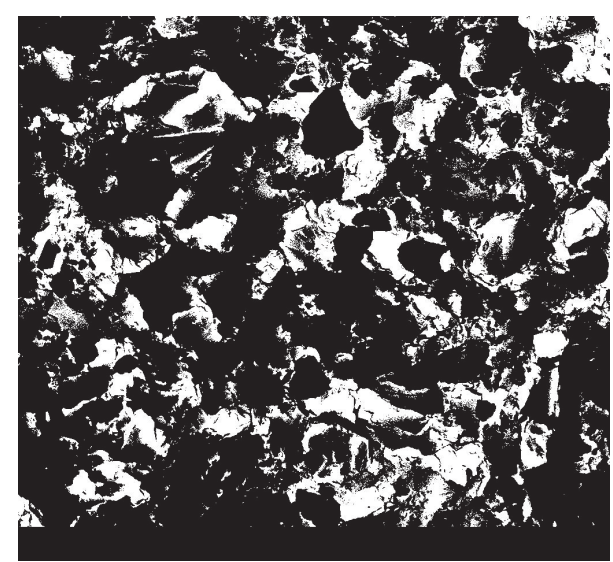

(b)

FIGURE 12: Binary images of sandstone with different moisture content (white: micropores): (a) 0.84\%; (b) $2.10 \%$.

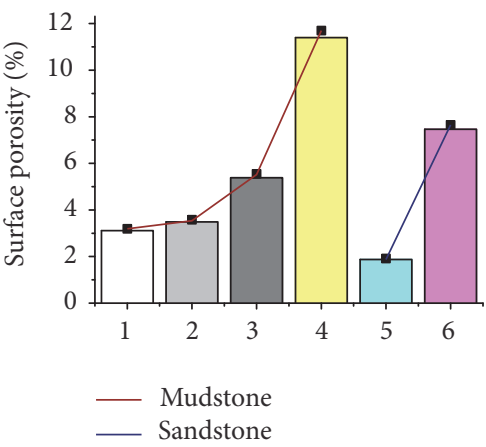

(a)

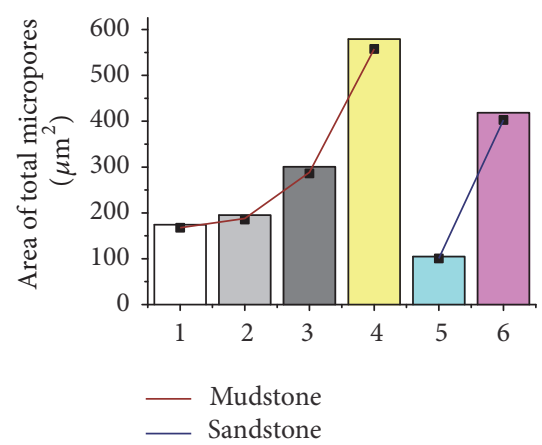

(b)

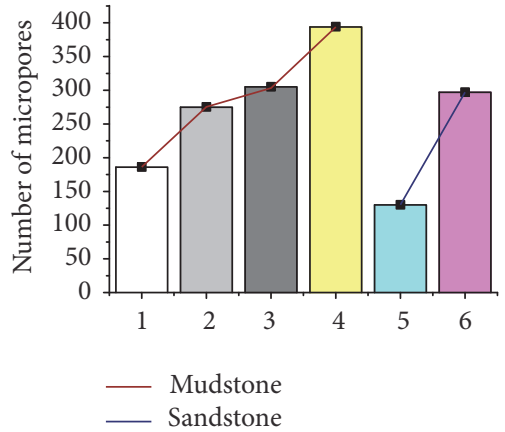

(c)

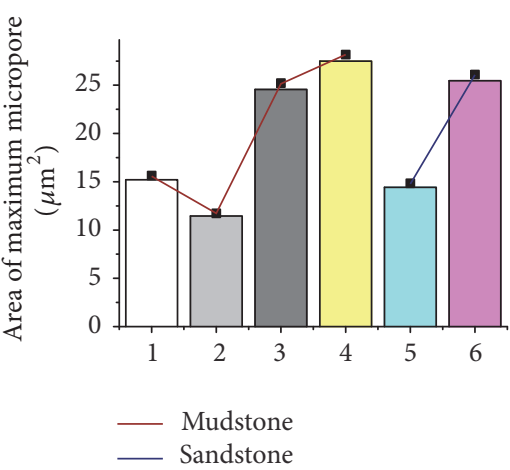

(d)

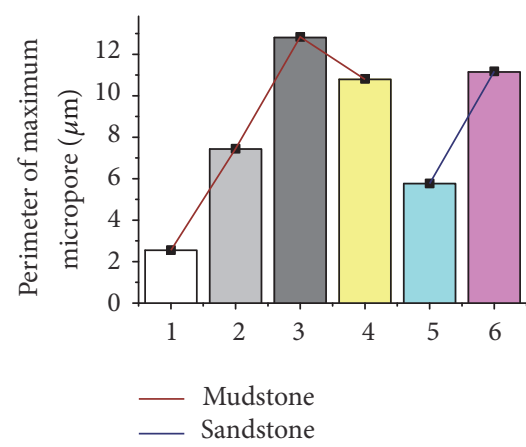

(e)

FIGURE 13: Histograms and line charts of parameter changes of micropores of mudstone and sandstone extracted from SEM images with different moisture content: (a) surface porosity; (b) area of total micropores; (c) number of micropores; (d) area of maximum micropores; (e) perimeter of maximum micropores (1 mudstone with moisture 1.54\%; 2 mudstone with moisture content $1.87 \%$; 3 mudstone with moisture content $2.96 \%$; 4 mudstone with moisture content $4.31 \%$; 5 sandstone with moisture content $0.84 \%$; 6 sandstone with moisture content $2.10 \%$ ).

various parameters required to develop the model of seepage and stress defined in further detail in Section 6.2.

(1) Equilibrium equation

$$
\frac{\partial \sigma_{i j}}{\partial x_{i j}}+\rho X_{j}=0, \quad(i, j=1,2,3) .
$$

(2) Geometric equation

$$
\begin{aligned}
\varepsilon_{i j} & =\frac{1}{2}\left(u_{i, j}+u_{j, i}\right), \\
\varepsilon_{v} & =\varepsilon_{11}+\varepsilon_{22}+\varepsilon_{33} .
\end{aligned}
$$




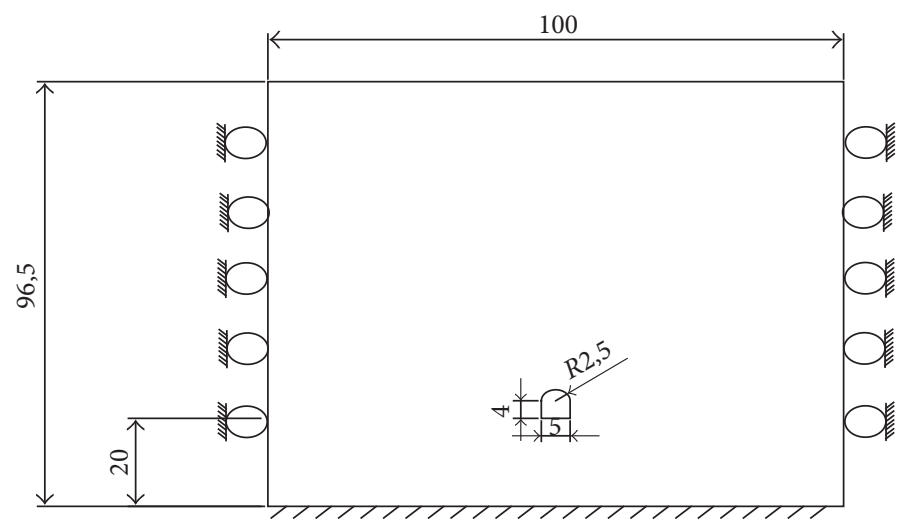

FIGURE 14: Calculation model of roadway excavation.

TABLE 4: Parameter variations of micropores of sandstone and mudstone with different moisture content.

\begin{tabular}{|c|c|c|c|c|c|c|}
\hline $\begin{array}{l}\text { Binary } \\
\text { images }\end{array}$ & SEM images & $\begin{array}{l}\text { Number of } \\
\text { micropores }\end{array}$ & $\begin{array}{c}\text { Total area of } \\
\text { micropores }\left(\mu \mathrm{m}^{\wedge 2}\right)\end{array}$ & $\begin{array}{l}\text { Area of maximum } \\
\text { micropore }\left(\mu \mathrm{m}^{\wedge 2}\right)\end{array}$ & $\begin{array}{c}\text { Diameter of } \\
\text { maximum } \\
\text { micropore }(\mu \mathrm{m})\end{array}$ & $\begin{array}{c}\text { Surface porosity } \\
(\%)\end{array}$ \\
\hline Figure $10(a)$ & Figure 9(a) & 186 & 174.30 & 15.21 & 2.55 & 3.11 \\
\hline Figure $10(b)$ & Figure 9(b) & 275 & 195.33 & 11.46 & 7.43 & 3.49 \\
\hline Figure 10(c) & Figure $9(\mathrm{c})$ & 305 & 300.47 & 24.55 & 12.81 & 5.38 \\
\hline Figure $10(d)$ & Figure $9(\mathrm{~d})$ & 394 & 579.26 & 27.50 & 10.79 & 11.4 \\
\hline Figure 12(a) & Figure 11(a) & 130 & 104.63 & 14.43 & 5.76 & 1.87 \\
\hline Figure 12(b) & Figure 11(b) & 297 & 418.31 & 25.46 & 11.15 & 7.46 \\
\hline
\end{tabular}

TABLE 5: Physical-mechanical parameters of surrounding rock (water content: 1.29\%).

\begin{tabular}{lcccccc}
\hline Type & $\begin{array}{c}\text { Tensile } \\
\text { strength/MPa }\end{array}$ & $\begin{array}{c}\text { Compression } \\
\text { strength/MPa }\end{array}$ & Cohesion/MPa & $\begin{array}{c}\text { Frictional } \\
\text { angle/ }\end{array}$ & $\begin{array}{c}\text { Density/ } \\
\left(\mathrm{kg} / \mathrm{m}^{\wedge 3}\right)\end{array}$ & $\begin{array}{c}\text { Young's } \\
\mathrm{modulus} / \mathrm{GPa}\end{array}$ \\
\hline $\begin{array}{l}\text { Surrounding } \\
\text { rock }\end{array}$ & 47.90 & 47.90 & 10.15 & 33.28 & 2600 & 10.17 \\
\hline
\end{tabular}

(3) Constitutive equation

$$
\sigma_{i j}^{\prime}=\sigma_{i j}-\alpha p \delta_{i j}=\lambda \delta_{i j} \varepsilon_{v}+2 G \varepsilon_{i j}
$$

(4) Seepage equation

$$
K_{i j} \nabla^{2} p=\frac{1}{Q} \frac{\partial p}{\partial t}-\alpha \frac{\partial \varepsilon_{v}}{\partial t} .
$$

(5) Seepage-stress relation equation

$$
K_{i j}(\sigma, p)=K_{0} \cdot e^{-a\left(\frac{\sigma_{i j}}{(3-\alpha p)}\right)} .
$$

6.2. Model Definition. As shown in Figure 14, the model is $100 \mathrm{~m}$ wide and $96.5 \mathrm{~m}$ high. A roadway is excavated $20 \mathrm{~m}$ above the bottom. The width of the roadway is $5 \mathrm{~m}$, the height of the roadway is $6.5 \mathrm{~m}$, and it has a semicircular radius at the top of $2.5 \mathrm{~m}$. The left and right boundaries of the model are roller boundaries, while the top and roadway surface are free boundaries. The bottom of the model has a fixed constraint boundary applied and there is a boundary load at the top of the model which represents the upper rock mass load.
The physical and mechanical parameters of the rock mass are list in Table 5, which were obtained from converting rock sample parameters to rock mass parameters using the HoekBrown strength criterion [25]. Different support pressures are applied so that the influence of support pressure on the roadway can be determined.

\subsection{Analysis}

6.3.1. Stress Distributions Analysis. Excavation alters the equilibrium state of in situ stress, resulting in the redistribution of in situ stresses around the roadway. Figure 15 illustrates the stress distributions in the vicinity of the underground roadway and Figure 16 shows the stress concentration at the corner of the roadway.

Stress concentration factors and stress nephograms at different moisture contents reflect not only the stress levels in rock mass but also the process of stress transfer and evolution. In general, both the center of the roof and floor undergo stress release after the roadway is excavated and form relief areas under and above the goaf, while the corners of the roadway concentrate stress and form pressurized areas. 


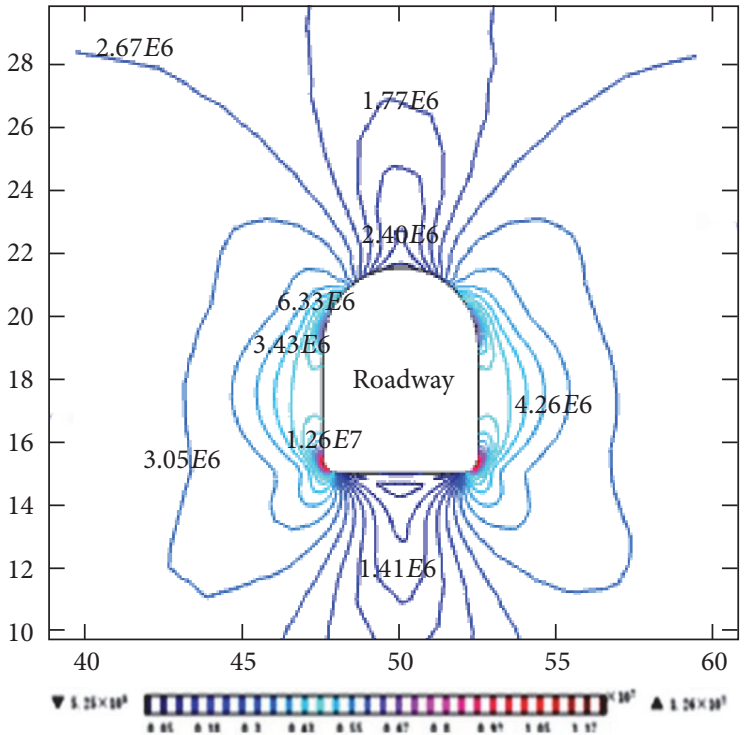

(a)

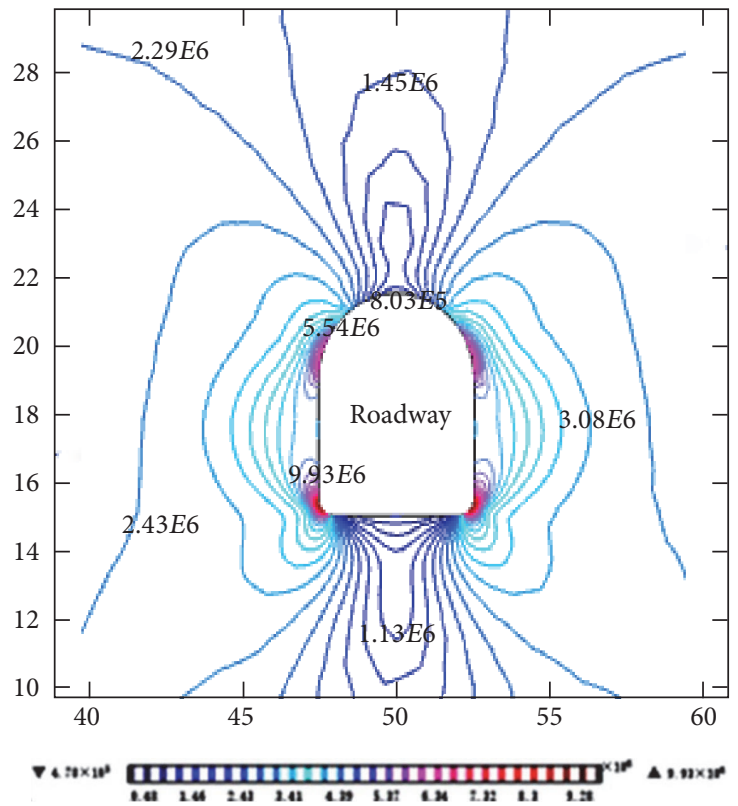

(c)

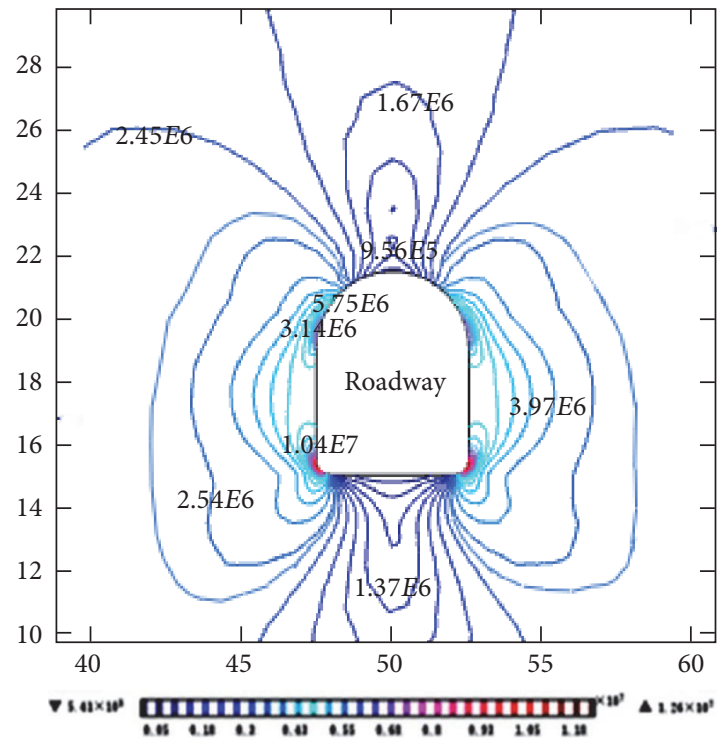

(b)

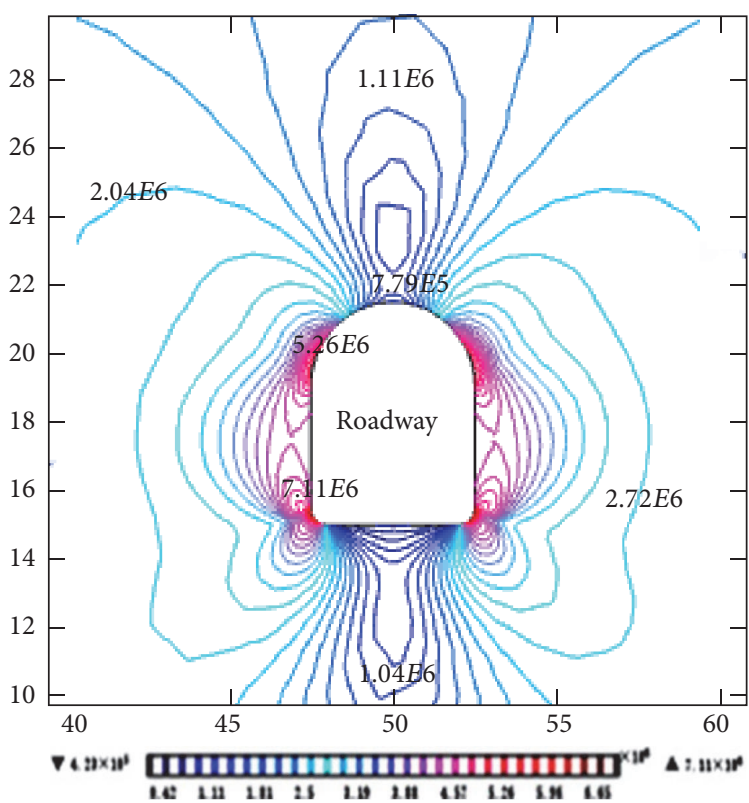

(d)

FIGURE 15: Stress distribution of surrounding rock on different moisture content.

When the moisture content is $0.5 \%$, the stress concentration factor around the roadway is 3.4 , which reduces to 2.54 when the moisture content is $2 \%$. It can be concluded that pressure has been released around the roadway, but the influenced regions related to roadway excavation will extend with increasing moisture content.

6.3.2. Vertical Displacement Analysis. Figure 17 shows vertical displacement nephograms when support pressure is $3 \mathrm{MPa}$. As can be seen, vertical displacement induced by roadway excavation decreases as the distance from the roadway increases, and subsidence will occur at the roof while the floor will heave up. The displacement region becomes larger because more stress is transferred to the rock mass as the moisture content increases. The absolute value of floor heave is larger than the roof subsidence because support pressure has been applied to the roof and ribs of the roadway.

Changes in roadway closure in the vertical direction are shown in Figure 18; when support pressure is low, roadway closure increases drastically as the moisture content increases. Support pressure can greatly improve roadway conditions since it will not only reduce roadway closure but also increase stability.

\section{Conclusions}

This investigation was conducted to study the mechanical properties and microstructural changes in mudstone and 


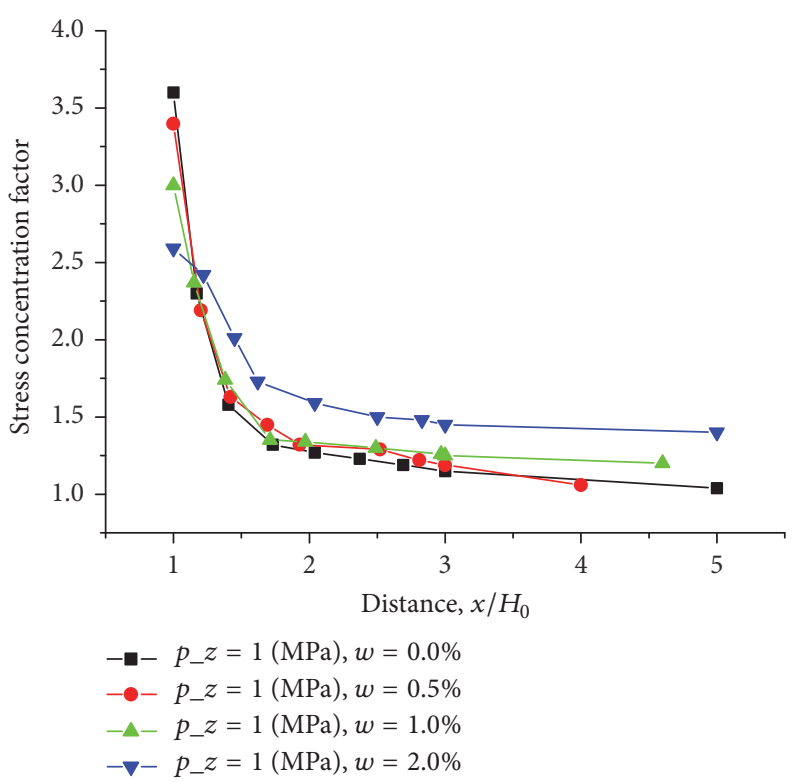

FIGURE 16: Stress concentration factor at the corner of roadway.

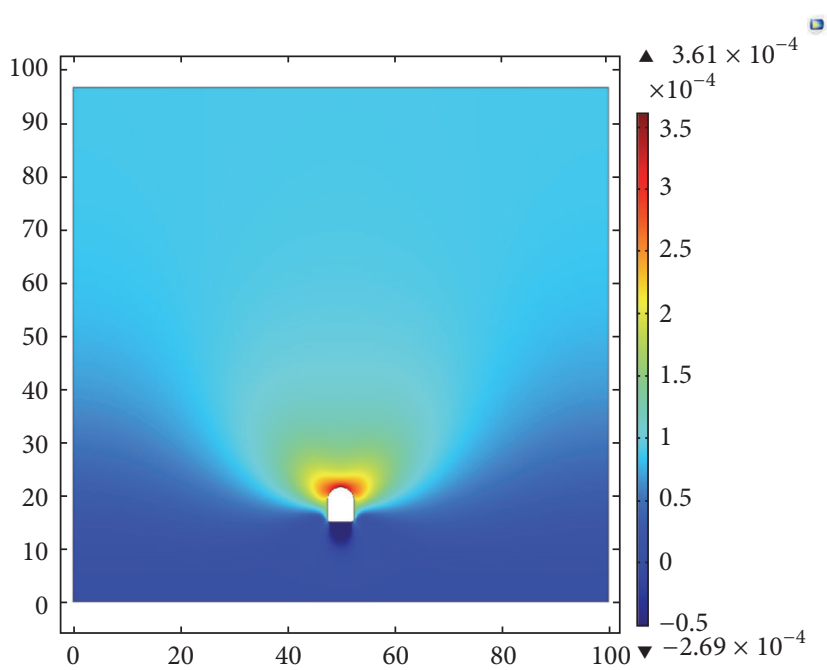

(a)

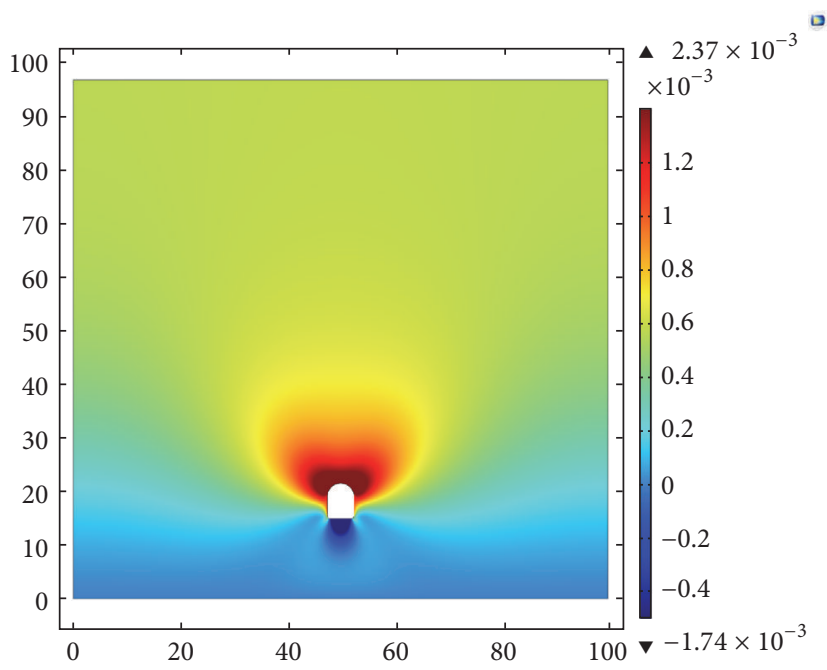

(c)

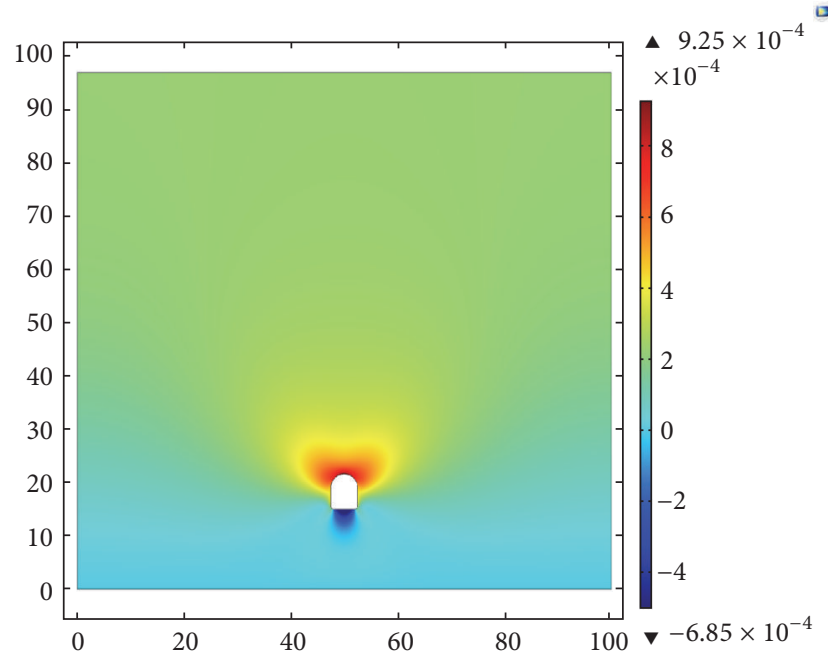

(b)

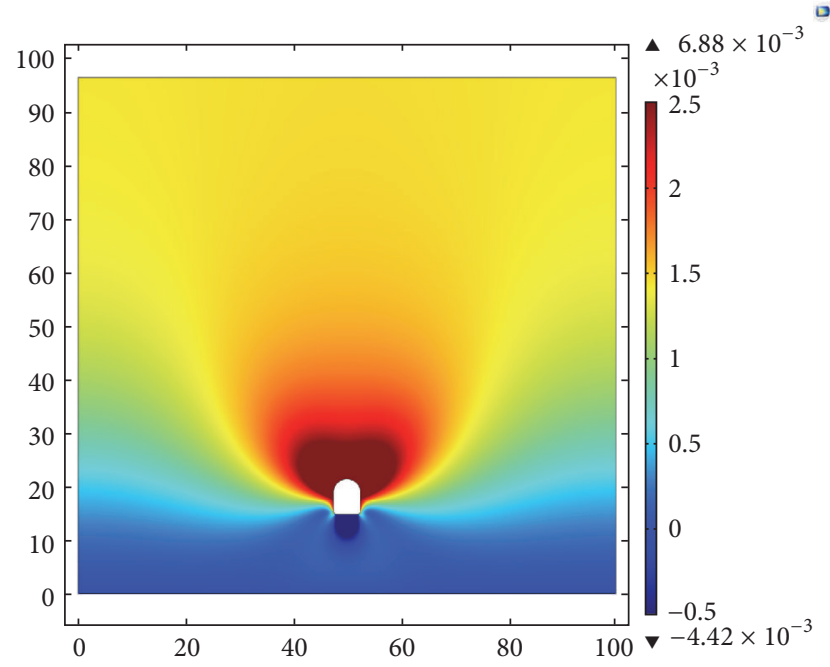

(d)

FIGURE 17: Vertical displacement of surrounding rock on different moisture content. 


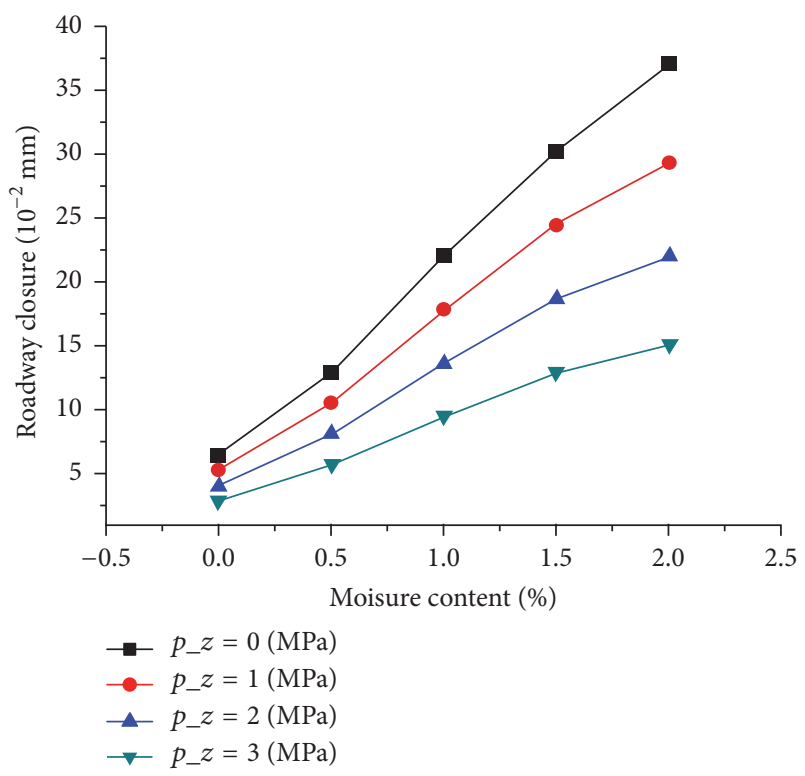

Figure 18: Roadway closure on different moisture content.

sandstone. Rock samples were collected from Permian siltstone and sandstone of the Shihezi Formation at depths of $616.8-665.3 \mathrm{~m}$ in the Tongting Colliery. Fluid-solid coupling effects were studied in terms of roadway stability and compared with different moisture contents in an underground roadway excavation simulation. Based on the results of this investigation, the following conclusions can be drawn:

(1) Mudstone in the investigated areas consists of a wide range of clay minerals, with kaolinite being the main clay mineral $(56.10 \%)$, while quartz and calcium silicate in the sandstone account for $70.20 \%$ and $27.10 \%$, respectively.

(2) In all cases, the moisture contents of mudstone and sandstone increased rapidly at the beginning of immersion test. After 9 days of immersion, the moisture content of mudstone and sandstone reached $4.97 \%$ and $2.27 \%$, respectively.

(3) All mechanical properties investigated showed a tendency to decrease with increasing moisture content. The general form $y=A \cdot \exp (-x / t)+B$ was found to describe the best-fit line for data points during regression analysis. The mechanical properties of the mudstone (compressive strength, cohesion, and internal friction angle) were found to be significantly lower than those of the sandstone.

(4) As the seepage of water into the samples increased (increasing moisture content), new pores and fractures were created and the original pores and fractures linked up, resulting in an increase in the number, total area, and diameter of micropores and surface porosity.

(5) Stress will be redistributed after roadway excavation and pressurized areas will occur near the corner of the roadway. Stress concentration at the corner will decrease, indicating a release of stress with increasing moisture content. At the same time, the influenced region caused by roadway excavation will extend. Vertical displacement and the influenced region will increase with increasing moisture content. The roadway closure has a positive correlation with the moisture content and support pressure plays a vital role in stabilizing the underground roadway.

$\begin{array}{ll}\text { Abbreviations } \\ \text { UCS: } & \text { Uniaxial compressive strength } \\ \text { SEM: } & \text { Scanning electron microscope } \\ \text { EDAX: } & \text { Energy dispersive X-ray analysis } \\ \text { XRD: } & \text { X-ray diffraction } \\ \text { ISRM: } & \text { International Society for Rock Mechanics } \\ \text { UHV: } & \text { Ultrahigh vacuum } \\ \text { HV: } & \text { High vacuum } \\ \text { LV: } & \text { Low vacuum } \\ p: & \text { Pore water pressure } \\ \alpha: & \text { Biot constants } \\ \delta: & \text { Kronecher constant } \\ K_{i j}: & \text { Permeability coefficient } \\ a: & \text { Coupling coefficient } \\ G: & \text { Shear modulus } \\ \sigma_{i j}: & \text { Total stress } \\ \sigma_{i j}^{\prime}: & \text { Effective stress } \\ \varepsilon_{i j}: & \text { Total strain. }\end{array}$

\section{Competing Interests}

The authors declare that there is no conflict of interests regarding the publication of this paper.

\section{Acknowledgments}

Thanks are due to National Key Research and Development Program (Project no. 2016YFC0600901); National Natural Science Foundation of China (Project no. 51574224); Natural Science Foundation of Jiangsu Province (Project no. BK20141130); Fundamental Research Funds for the Central Universities (Project no. 2014QNB27).

\section{References}

[1] Z. Youtian, Rock Hydraulics and Engineering, China Waterpower Press, Beijing, China, 2005.

[2] Z.-X. Li, Y.-S. Pan, and Z.-H. Zhang, "Layout of drill hole and the determination of parameter in advanced water injection to prevent rockburst from occurring," Journal of the China Coal Society, vol. 29, no. 6, pp. 684-688, 2004.

[3] D. Song, E. Wang, Z. Liu, X. Liu, and R. Shen, "Numerical simulation of rock-burst relief and prevention by water-jet cutting," International Journal of Rock Mechanics and Mining Sciences, vol. 70, pp. 318-331, 2014.

[4] E. M. Van Eeckhout and S. S. Peng, "The effect of humidity on the compliances of coal mine shales," International Journal of Rock Mechanics \& Mining Sciences \& Geomechanics Abstracts, vol. 12, no. 11, pp. 335-340, 1975. 
[5] P. Colback, B. Wiid, P. S. B. Colback et al., "The influence of moisture content on the compressive strength of rocks," Geophysics, 1900.

[6] E. Z. Lajtai, R. H. Schmidtke, and L. P. Bielus, "The effect of water on the time-dependent deformation and fracture of a granite," International Journal of Rock Mechanics \& Mining Sciences \& Geomechanics Abstracts, vol. 24, no. 4, pp. 247-255, 1987.

[7] O. Ojo and N. Brook, "The effect of moisture on some mechanical properties of rock," Mining Science and Technology, vol. 10, no. 2, pp. 145-156, 1990.

[8] S. Okubo, Y. Nishimatsu, C. He, and S. Y. Chu, "Loading rate dependency of uniaxial compressive strength of rock under water-saturated condition," Journal of the Society of Materials Science, Japan, vol. 41, no. 463, pp. 403-409, 1992.

[9] A. B. Hawkins and B. J. Mcconnell, "Sensitivity of sandstone strength and deformability to changes in moisture content," Quarterly Journal of Engineering Geology \& Hydrogeology, vol. 25, no. 2, pp. 115-130, 1992.

[10] F. Valès, D. N. Minh, H. Gharbi, and A. Rejeb, "Experimental study of the influence of the degree of saturation on physical and mechanical properties in Tournemire shale (France)," Applied Clay Science, vol. 26, no. 1-4, pp. 197-207, 2004.

[11] Q. T. Pham, F. Vales, L. Malinsky, D. Nguyen Minh, and H. Gharbi, "Effects of desaturation-resaturation on mudstone," Physics and Chemistry of the Earth, vol. 32, no. 8-14, pp. 646655, 2007.

[12] Z. A. Erguler and R. Ulusay, "Estimation of Uniaxial Compressive Strength of Clay-bearing Weak Rocks Using Needle Penetration Resistance," 2007.

[13] J. Zhou, X. Chen, L. Wu, and X. Kan, "Influence of free water content on the compressive mechanical behaviour of cement mortar under high strain rate," Sādhanā, vol. 36, no. 3, pp. 357369, 2011.

[14] G. Gianelli, Y. Yusa, S. Battaglia, and K. Takemura, "Water-rock interaction in a zone of lateral flow: a natural example from the active geothermal field and gold-mineralized zone of Beppu (Kyushu Island, Japan)," Mineralogy and Petrology, vol. 45, no. 3, pp. 247-259, 1992.

[15] B. Chai, K.-L. Yin, W.-X. Jian, and Y.-X. Dai, "Analysis of waterrock interaction characteristics and bank slope failure process of red-bed," Zhongnan Daxue Xuebao, vol. 40, no. 4, pp. 10921098, 2009.

[16] R. A. Duraiswami and T. N. Shaikh, "Fluid-rock interaction in the Kangankunde Carbonatite Complex, Malawi: SEM based evidence for late stage pervasive hydrothermal mineralisation," Open Geosciences, vol. 6, no. 4, pp. 476-491, 2016.

[17] B. Chai, J. Tong, B. Jiang, and K. Yin, "How does the water-rock interaction of marly rocks affect its mechanical properties in the Three Gorges reservoir area, China?" Environmental Earth Sciences, vol. 72, no. 8, pp. 2797-2810, 2014.

[18] M. Y. Çelik, H. Akbulut, and A. Ergül, "Water absorption process effect on strength of Ayazini tuff, such as the uniaxial compressive strength (UCS), flexural strength and freeze and thaw effect," Environmental Earth Sciences, vol. 71, no. 9, pp. 4247-4259, 2014.

[19] X. W. Zhang, L. W. Kong, X. L. Cui, and S. Yin, "Occurrence characteristics of free iron oxides in soil microstructure: evidence from XRD, SEM and EDS," Bulletin of Engineering Geology and the Environment, vol. 75, no. 4, pp. 1493-1503, 2015.

[20] R. M. Koerner and Y. G. Hsuan, "Geosynthetics: characteristics and testing," in Geotechnical and Geoenvironmental Engineering Handbook, pp. 173-196, Springer US, Berlin, Germany, 2001.
[21] E. Garrison, "X-Ray Diffraction (XRD): applications in archaeology," in Encyclopedia of Global Archaeology, pp. 7929-7933, Springer, New York, NY, USA, 2014.

[22] L. S. Zevin and G. Kimmel, Quantitative X-Ray Diffractometry, Springer, New York, NY, USA, 1995.

[23] ISRM, "The complete ISRM suggested methods for rock characterization, testing and monitoring: 1974-2006," in Suggested Methods Prepared by the Commission on Testing Methods, R. Ulusay and J. A. Hudson, Eds., pp. 85-216, International Society for Rock Mechanics, 2007.

[24] R. Reichelt, "Scanning electron microscopy," in Science of Microscopy, P. W. Hawkes and J. C. H. Spence, Eds., pp. 133-272, Springer, New York, NY, USA, 2007.

[25] E. Hoek and E. T. Brown, "Practical estimates of rock mass strength," International Journal of Rock Mechanics and Mining Sciences, vol. 34, no. 8, pp. 1165-1186, 1997. 


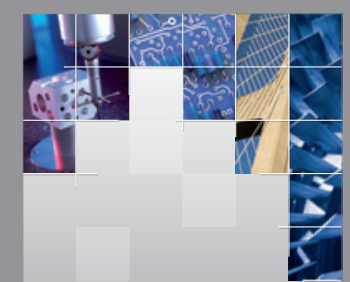

\section{Enfincering}
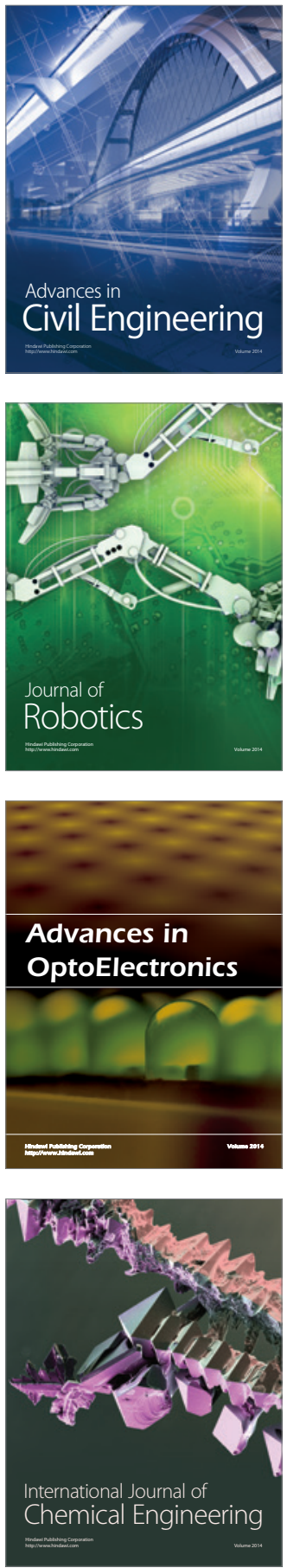

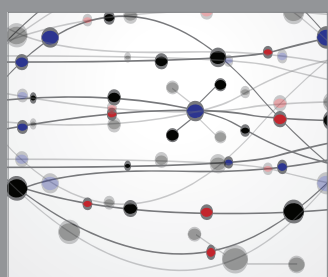

The Scientific World Journal

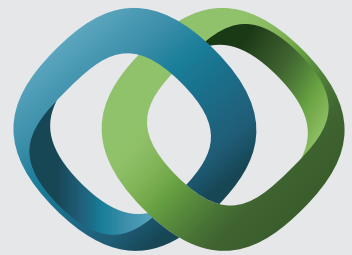

\section{Hindawi}

Submit your manuscripts at

https://www.hindawi.com
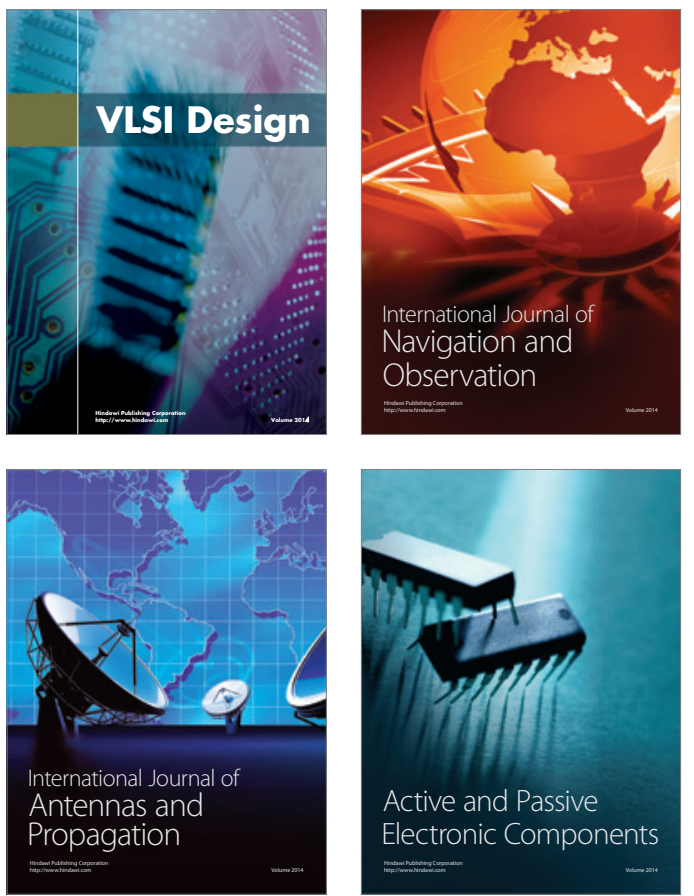
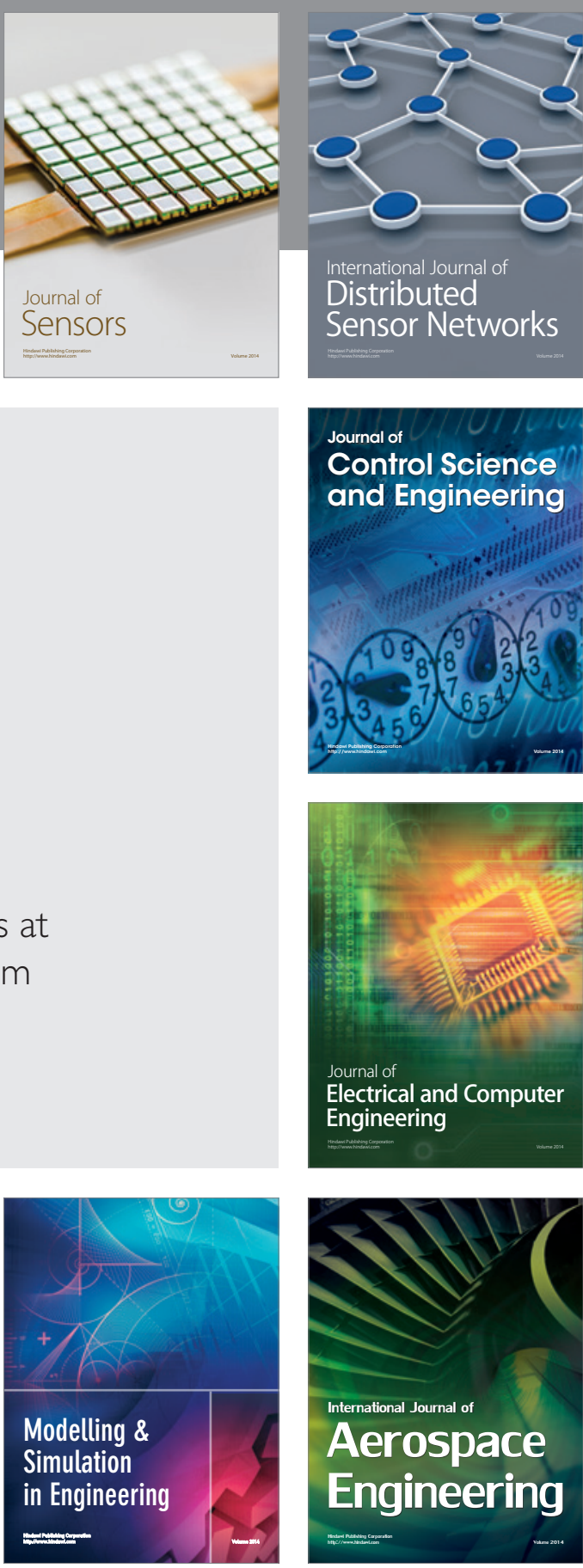

International Journal of

Distributed

Sensor Networks

$-$

Joumal of

Control Science

and Engineering
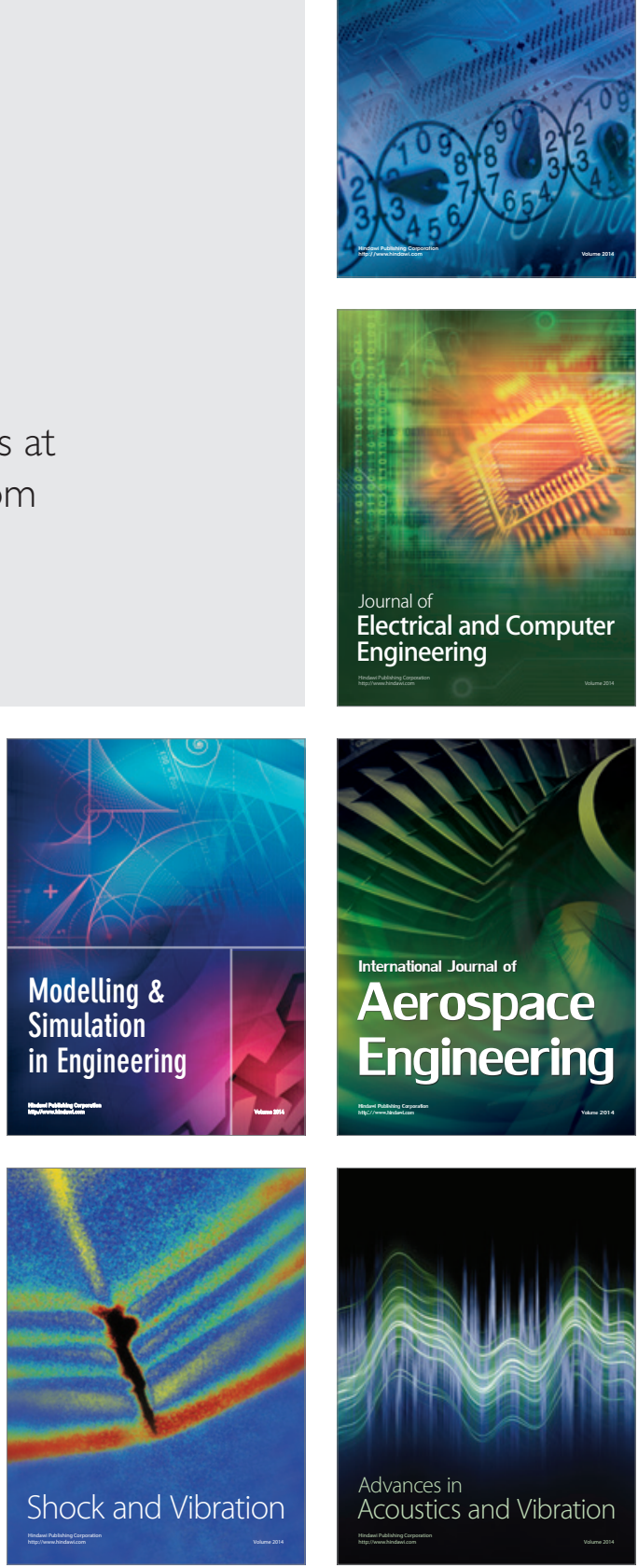